\title{
The EGS Collab Project: An intermediate-scale field test to address enhanced geothermal system challenges
}

\author{
Timothy Kneafsey ${ }^{1, *}$ and the EGS Collab Team ${ }^{2 \dagger}$ \\ ${ }^{1}$ Energy Geosciences Division, Lawrence Berkeley National Laboratory, Berkeley, California, USA \\ ${ }^{2}$ Sandia National Laboratories, Lawrence Livermore National Laboratory, Pacific Northwest National Laboratory, Idaho National \\ Laboratory, Los Alamos National Laboratory, National Renewable Energy Laboratory, Oak Ridge National Laboratory, National Energy \\ Technology Laboratory, Sanford Underground Research Facility, Colorado School of Mines, University of Oklahoma, Penn State \\ University, Rice University, South Dakota School of Mines and Technology, Stanford University, University of Wisconsin, TDoe Geo, \\ ResFrac, Mattson Hydrogeology
}

\begin{abstract}
Three components are typically needed to extract geothermal energy from the subsurface: 1 . hot rock, 2. a heat transfer fluid, and 3. flow pathways contacting the fluid and the rock. These naturally occur in many locations resulting in hydrothermal systems, however there are enormous regions containing hot rock that do not naturally have adequate fluid, and/or appropriate fluid permeability to allow hot fluid extraction. Some type of engineering or enhancement of these systems would be required to extract the energy. These enormous regions provide the possibility of long-term extraction of significant quantities of energy. Enhanced (or engineered) Geothermal Systems (EGS) are engineered reservoirs created to extract economical amounts of heat from low permeability and/or porosity geothermal resources. There are technological challenges that must be addressed in order to extract the heat. These include proper stimulation, effective monitoring, reservoir control, and reservoir sustainability. The US DOE Geothermal Technologies Office and geothermal agencies from other countries have supported field tests over a range of scales and conditions. A current US field project, the EGS Collab Project, is working nearly a mile deep in crystalline rock at the Sanford Underground Research Facility (SURF) to study rock stimulation under EGS stress conditions. We are creating intermediate-scale (tens of meters) test beds via hydraulic stimulation and are circulating chilled water to model the injection of cooler water into a hot rock which would occur in an EGS, gathering high resolution data to constrain and validate thermal-hydrological-mechanical-chemical (THMC) modeling approaches. These validated approaches would then be used in the DOE's flagship EGS field laboratory, Frontier Observatory for Research in Geothermal Energy (FORGE) underway in Milford, Utah and in commercial EGS. In the EGS Collab project, numerous stimulations have been performed, characterized, and simulated and long-term flow tests have been completed.
\end{abstract}

\footnotetext{
* Corresponding author : tjkneafsey@1bl.gov

$\dagger$ J. Ajo-Franklin, T. Baumgartner, K. Beckers, D. Blankenship, A. Bonneville, L. Boyd, S. Brown, J.A. Burghardt, C. Chai, Y. Chen, B. Chi, K. Condon, P.J. Cook, D. Crandall, P.F. Dobson, T. Doe, C.A. Doughty, D. Elsworth, J. Feldman, Z. Feng, A. Foris, L.P. Frash, Z. Frone, P. Fu, K. Gao, A. Ghassemi, Y. Guglielmi, B. Haimson, A. Hawkins, J. Heise, C. Hopp, M. Horn, R.N. Horne, J. Horner, M. Hu, H. Huang, L. Huang, K.J. Im, M. Ingraham, E. Jafarov, R.S. Jayne, S.E. Johnson, T.C. Johnson, B. Johnston, K. Kim, D.K. King, T. Kneafsey, H. Knox, J. Knox, D. Kumar, M. Lee, K. Li, Z. Li, M. Maceira, P. Mackey, N. Makedonska, E. Mattson, M.W. McClure, J. McLennan, C. Medler, R.J. Mellors, E. Metcalfe, J. Moore, C.E. Morency, J.P. Morris, T. Myers, S. Nakagawa, G. Neupane, G. Newman, A. Nieto, C.M. Oldenburg, T. Paronish, R. Pawar, P. Petrov, B. Pietzyk, R. Podgorney, Y. Polsky, J. Pope, S. Porse, J.C. Primo, C. Reimers, B.Q. Roberts, M. Robertson, W. Roggenthen, J. Rutqvist, D. Rynders, M. Schoenball, P. Schwering, V. Sesetty, C.S. Sherman, A. Singh, M.M. Smith, H. Sone, E.L. Sonnenthal, F.A. Soom, P. Sprinkle, C.E. Strickland, J. Su, D. Templeton, J.N. Thomle, V.R. Tribaldos, C. Ulrich, N. Uzunlar, A. Vachaparampil, C.A. Valladao, W. Vandermeer, G. Vandine, D. Vardiman, V.R. Vermeul, J.L. Wagoner, H.F. Wang, J. Weers, N. Welch, J. White, M.D. White, P. Winterfeld, T. Wood, S. Workman, H. Wu, Y.S. Wu, E.C. Yildirim, Y. Zhang, Y.Q. Zhang, Q. Zhou, M.D. Zoback
}

\footnotetext{
* Corresponding author: tjkneafsey@lbl.gov
} 


\section{Introduction}

Three components are typically needed to extract geothermal energy from the subsurface: 1 . hot rock, 2 . a heat transfer fluid - typically water or brine, although carbon dioxide has been considered, and 3. flow pathways that provide proper heat transfer contact between the fluid and the rock. These combined components occur naturally in many locations resulting in hydrothermal systems, however there are enormous regions containing hot rock that do not have adequate fluid, and/or appropriate fluid permeability. In these locations, engineering or enhancing the system is required to extract the energy. These enormous regions provide the possibility of long-term extraction of significant quantities of energy.

Enhanced (or engineered) Geothermal Systems (EGS) are engineered reservoirs created to extract economical amounts of heat from low permeability and/or porosity geothermal resources. EGS offer tremendous potential as an energy resource. Estimates of the EGS resources in the western US could exceed 500 GWe, surpassing conventional hydrothermal systems resources [1]. When considering the entire United States, Augustine [2] estimated that the EGS resource could be ten times larger. The magnitude of these resource estimates makes EGS attractive to utilize. There are technological challenges, however, where improvements are needed. These include: (1) effective stimulation techniques to suitably create subsurface "heat exchangers" that communicate between multiple wells by fractures in different rock types and under different stress conditions, (2) techniques to image/monitor permeability enhancement and evolution at the reservoir scale at the resolution of individual fractures, (3) additional technologies for zonal isolation for multistage stimulations under elevated temperatures, (4) technologies to isolate zones for controlling fast flow paths that result in early thermal breakthrough, and (5) scientifically-based long-term EGS reservoir sustainability and management techniques [3].

EGS resource creation requires accessibility to the rock. A flow loop is required requiring multiple expensive boreholes to inject and extract water. Due to the expense, drilling must be optimized. Injected water must contact the hot reservoir rock to extract thermal energy. In situ hydrologic, lithologic, and geologic conditions must be adequately known and considered in the design of the fracture system (heat exchanger). Available water must be injected and circulated through the reservoir, and heated water must be extracted via at least one other drilled well. Sufficient quantities of water heated to a high enough temperature, may be used to produce electricity economically. Reasonable parameters for electricity production require about $50 \mathrm{~kg} / \mathrm{s}$ from a $200^{\circ} \mathrm{C}$ body of rock, with no more than $10^{\circ} \mathrm{C}$ temperature drop in the produced fluid over a 30 year project life [4]. Heat from lower temperature fluids or flow at lower rates might be used for purposes other than electricity production (heating universities, military bases, greenhouses) depending on economics. Vast quantities of hot rock are present in the arid western United States; thus, water resource management and recycling will be required.
Investigations of EGS-related elements including zonal isolation, improved drilling, and waterless stimulation have been and continue to be performed. Field tests have also been performed at a number of locations around the world, each contributing knowledge towards understanding EGS. The US DOE Geothermal Technologies Office (GTO) and geothermal agencies from other countries have supported field tests over a range of scales and conditions to address the technological challenges and reduce the risks of implementing EGS. Two current field test projects in the US include the Frontier Observatory for Research in Geothermal Energy (FORGE) and the EGS Collab Project.

\section{FORGE}

The FORGE project is creating a subsurface research laboratory allowing investigations of EGS processes at the full field scale in rock having a temperature between 175 and $225 \mathrm{C}$. The intent of the FORGE Project is to provide a heavily instrumented research site for developing, testing, and accelerating breakthroughs in EGS technologies to enable a commercial pathway for EGS technologies. There is no expectation of producing electrical power at the site. The goals of the FORGE project are to (1) provide an underground laboratory for developing and testing innovative tools and stimulation techniques for developing EGS reservoirs, (2) extend existing technologies developed for oil and gas beyond current capabilities to successfully produce electricity from hot crystalline rocks, (3) demonstrate technologies that can be applied across the US, (4) provide domestic and international scientists and students with funds for research to expand future energy security and availability, and (5) demonstrate suitability and safety of large-scale geothermal energy development to the public.

After a rigorous selection process considering several locations, a low permeability site on the flank of the Roosevelt Hot Springs Geothermal Field was selected. At this site, a large volume of hot crystalline granite will be accessible between two deep directionally drilled wells at around 8000 feet depth. The project is managed by a multidisciplinary team of engineers and scientists from universities, national laboratories, federal and state funded institutions, and private industry led by the University of Utah [5].

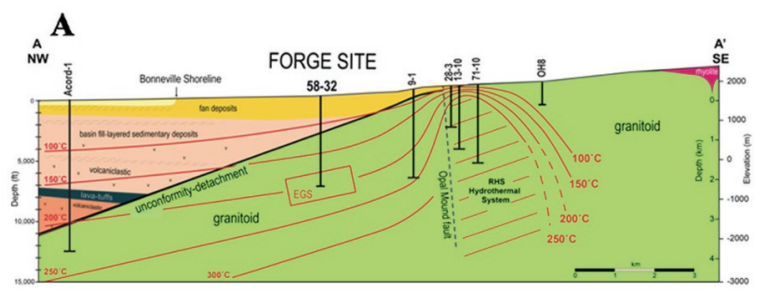

Fig. 1. Cross section of the Utah FORGE site (from Moore, 2019).

FORGE investigations will begin in 2020 during facility construction and continue through 2024 and include competitive funding rounds, open for public

\footnotetext{
* Corresponding author: tjkneafsey@lbl.gov
} 
application to attract outstanding programs of innovative research and development. During site development, investigations to improve drilling, stimulation, injectionproduction, and subsurface geophysical imaging technologies will be performed. These will help establish and sustain continuous fluid flow and energy transfer from an EGS reservoir.

\section{EGS Collab Project}

To improve understanding of subsurface heat exchange in crystalline rock, the GTO established the EGS Collab project. Working at nearly a mile deep in the Sanford Underground Research Facility (SURF) to simulate EGS stress conditions, the project is creating intermediatescale (10's of meters) test beds via hydraulic stimulation and is circulating chilled water to model the injection of cooler water into a hot rock as would occur in an EGS.

The project is a collaborative multi-lab and university research endeavor bringing together a team of skilled and experienced researchers and engineers in the areas of subsurface process modeling, monitoring, and experimentation to focus on intermediate-scale EGS reservoir creation processes and related model validation in crystalline rock.

The project has planned three multi-test experiments to increase understanding of 1) hydraulic fracturing (Experiment 1- now complete), 2) shear stimulation (Experiment 2 - design underway at the time of writing), and 3) other stimulation methods (Experiment 3). Each series of tests within an experiment begins with modeling to support experiment design, and post-test modeling and analysis are performed to examine the effectiveness of our modeling tools and approaches. By doing this, we can gain confidence in and improve the array of modeling tools in use. In Experiment 1, we performed several highly monitored hydraulic fracture stimulations and flow tests, and implemented a suite of rock/reservoir characterization methods potentially useful for EGS systems, as well as other methods available to improve understanding $[6,7]$.

\subsection{Experiment 1}

Experiment 1 was intended to establish a fracture network to connect an injection well and a production well using hydraulic fracturing [8]. The site was selected adjacent to the KISMET site, where hundreds of meters of vertical boring identified a competent rock with few open fractures [9]. A schematic of the Experiment 1 testbed is shown in Figure 2. All boreholes for the experiment are nominally 60 meters long, drilled subhorizontally, and continuously cored. The injection and production boreholes (green and red lines in Figure 2) were drilled in approximately the minimum principal stress direction based on prior characterizations performed in adjacent rock [9] so that hydraulic fractures would tend to propagate orthogonally to the injection well. Interestingly, although the kISMET cores indicated few fractures, numerous fractures were identified in the EGS Collab testbed.
Boreholes were characterized using numerous well logging tools (temperature, conductivity, optical televiewer, acoustic televiewer, resistivity, full waveform sonic). A range of geophysical and hydraulic techniques were used to characterize the rock, including microseismic monitoring (MEQ), continuous activesource seismic monitoring (CASSM), distributed acoustic sensing (DAS), distributed temperature sensing (DTS), electrical resistance tomography, and step-pressure and tracer tests. Tracer tests were designed to help define the effective heat transfer surface area and determine the flow rate limitations for sustaining production well temperatures [10, 11]. We are also using monitoring methods that are currently unable to work under geothermal reservoir conditions. Long-term thermal circulation experiments are key to validate predictions based on field data and stimulations.

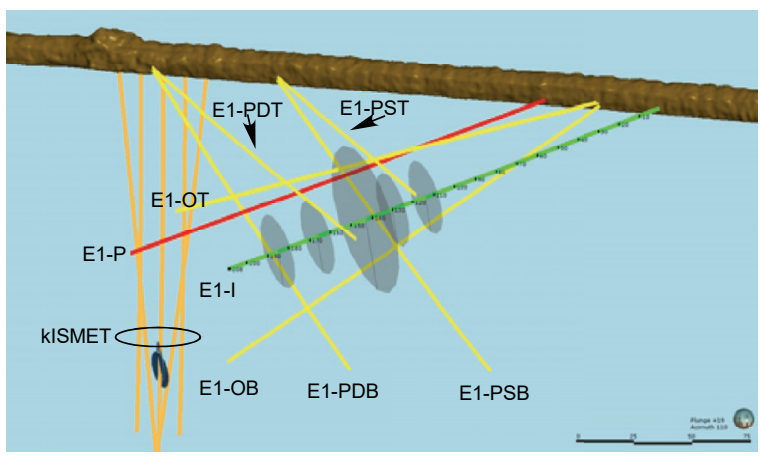

Fig. 2. Schematic of wells for Experiment 1 along the West Drift on the 4850 level of SURF. The green line represents the stimulation (Injection) well (E1-I), the red line represents the Production well (E1-P), yellow lines represent monitoring wells, and orange lines represent kISMET wells. The two monitoring wells originating between E1-I and E1-P - rightmost intersection with the brown drift are called OT " $\mathrm{O}$ " for orthogonal to the anticipated hydraulic fracture and "T" for top) and OB ("B" for bottom), the 2 monitoring wells originating midway down-drift are called PST and PSB ("P" for parallel to the anticipated fracture plane, "S" is for shallow), and the most distant monitoring wells are called PDT and PDB where the "D" is for deep. Orientation of stimulation and production boreholes is approximately parallel to $\mathrm{Shmin}_{\mathrm{h}}$ and the gray disks indicate nominal hydraulic fractures.

Four stimulation tests were performed followed by short- and long-term ambient temperature and chilled water flow tests, resulting in many data sets and analyses [12-27]. Prior to stimulation, notches were scribed using a custom notching tool at locations along the injection well to encourage perpendicular fracturing [28]. The first stimulation attempt was performed at the 142 ' Notch (142 feet from the collar of E1-I). The packer interval (approximately 65 inches including the Step-rate Injection Method for Fracture In-situ Properties (SIMFIP) tool $[29,30]$ encompassed a large apparently healed natural fracture. The stimulation was planned to occur in steps. The initial stimulation was designed such that it might create an ideal $1.5 \mathrm{~m}$ radius penny-shaped fracture, followed by shutting in the well for the night. The second step would extend the fracture to $5 \mathrm{~m}$ radius followed by shutting in for the night, and the third step would extend 
the fracture to the production borehole approximately 10 $\mathrm{m}$ away. At the 142' Notch, pressurizing led to an unacceptable amount of water flow returning up the borehole and a much higher-than-expected fracture initiation pressure. Our analysis indicates that a hydraulic fracture was created with a breakdown pressure of 31 $\mathrm{MPa}$ (4500 psi), and this fracture probably intersected the observed natural fracture. A total of twelve liters of water were injected in this test. Because shear stimulation was not intended in this test and the results indicated that we might be pumping into the natural fracture where shear could occur, the stimulation packer set was moved downhole to center on the 164' Notch. White et al. [13] presents an excellent summary of the tests performed, Kneafsey et al. [3] summarizes short-term flow tests, and tracer tests are summarized in Mattson et al. [31].

At the 164 ' Notch, the stimulation was carried out in steps over three days with shut-in periods between each step. In the first step, $2.1 \mathrm{~L}$ of water was injected at a flow rate of $200 \mathrm{~mL} / \mathrm{min}$. The pressure required to propagate the fracture was $25.43 \mathrm{MPa}(3688 \mathrm{psi}$ ), and the instantaneous shut-in pressure (ISIP) was $25.37 \mathrm{MPa}$ (3679 psi). In the second step, $23.5 \mathrm{~L}$ of water was injected at $400 \mathrm{~mL} / \mathrm{min}$ and the propagation pressure and ISIP were 25.95 and $25.82 \mathrm{MPa}$ respectively (3763 and 3744 psi). Pressure decayed rapidly after this step indicating that the hydraulic fracture may have intersected a natural fracture. The third step was performed at $5 \mathrm{~L} / \mathrm{min}$, had an injection volume of $80.6 \mathrm{~L}$, and resulted in a propagation pressure and ISIP of 26.88 and 25.31 $\mathrm{MPa}$ (3898 psi and $3670 \mathrm{psi}$ ). Water was produced at E1$\mathrm{P}$ during this step indicating completion of the flow loop. In addition to intersecting the production well, this stimulation intersected the E1-OT monitoring well (located between the injection and production boreholes). This intersection was indicated by the seismic sensors, a temperature increase measured by the DTS, and eventually water leaking out the top of the grouted E1-OT well, providing ground-truth data for these geophysical methods. Leakage from E1-OT was problematic, requiring remediation.

The third stimulation was conducted at the 128' Notch, attempting to avoid a fracture that connects wells E1-OT and E1-P (the "OT-P connector") while still connecting the injection and production wells. In this stimulation, flow bypassed the top injection packer through fractures. This test also resulted in a hydraulic fracture connecting with E1-OT, but not E1-P.

Following the third stimulation, hydraulic characterization tests were conducted at the 164' Notch. Another stimulation experiment was later completed at the 142 ' Notch by carefully placing the packer over fractures of concern. High flow rates and pressures were applied, and at least one hydraulic fracture was extended to E1-OB and E1-P. From DTS evidence, the fracture connected with all other wells except for E1-PDB. We only intended to connect the injection well to the production well, but not to the monitoring wells. These extra connections were at times problematic, but also offered the opportunity to directly compare geophysical monitoring methods. Micro-seismic event locations [24] consistently indicate that the fracture extended toward the drift for the stimulations at both the $164 \mathrm{ft}$ and $142 \mathrm{ft}$ notches. This was predicted by earlier modeling of fracture growth under the stress gradient created by thermal cooling of the rock by the drift $[32,33]$.

Chilled water injection tests were performed for 10 months in this well-characterized rock mass. Conservative, nonconservative, reactive, and DNA tracers and numerous types of geophysical instrumentation, are being used to inform and constrain thermal-hydrological-mechanical-chemical modeling approaches for validation of utility.

(THMC)

\subsection{Experiment 2}

The second EGS Collab experiment is currently being planned. It is expected to be performed in the Yates amphibolite on the 4100 level at SURF. A schematic of the region of the mine and anticipated boreholes is presented in Figure 3. A vertical and a short horizontal borehole have been cored to investigate fracture and rock conditions, and a number of mini-frac tests and SIMFIP tests have been performed in the vertical hole to identify the directions of the stresses and the magnitude of the minimum principal stress. Interestingly, the minimum principal stress varies significantly over the $50 \mathrm{~m}$ depth of the hole, being higher than expected below a rhyolite layer intersected in the lower third of the hole, lower than expected within the rhyolite layer, and intermediate above the rhyolite layer. A number of fracture sets have been identified in the core and logging. These data were used to optimize the orientation of the injection well to induce a shear stimulation of the rock.

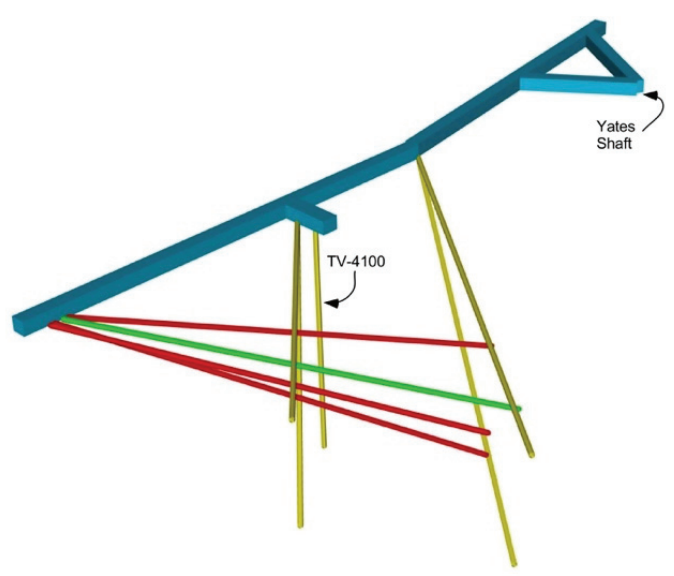

Fig. 3. Probable well orientations for Experiment 2. The thick blue line represents the drift, the green line represents the injection well, red lines represent production wells, and yellow lines represent monitoring wells. Other than the vertical well TV4100, all wells are subhorizontal.

\subsection{Major Observations}

Scientific observations fall into several major categories: general, poroelasticity, thermoelasticity, and local geology. 


\subsubsection{General}

The EGS Collab project has used several methods of quantifying fracture opening and closure. Spatially imaged fracture opening using continuous active source seismic monitoring showed opening within the monitored region upon pressurization $[3,34,35]$. The SIMFIP tool was also used to quantify rock motion across a fracture or fractured zone [3] in a borehole during stimulation, and in a number of stimulations in a vertical borehole on the 4100 level. These quantifications provide key insights into stimulation.

It is still not clear whether or how well heat transfer area can be predicted using the results of chemical tracer tests. This comparison is extremely important for EGS.

The intersection of a stimulated fracture with a borehole containing a DTS fiber indicated temperatures measured were higher than expected from heat convection and conduction. This increased temperature can be explained by the Joule-Thomson effect with the sudden decrease in water pressure upon entering the well [36]. The known location of the fracture intersection with the monitoring well indicated by the DTS provided a validation point for the inversion of microseismic monitoring data, indicating that the inversions provided accurate event locations.

\subsubsection{Poroelasticity}

Poroelasticity appears to play an important role in rockfracture system response to fluid circulation. The fractures created in Experiment 1 are viewed as hydropropped (opened by fluid pressure). In our many starts and stops the injection pressure required to flow water at the same flow rate always increased over time. A shut down, even very brief, resulted in a significantly lower pressure required to inject that same rate upon restarting. The poroelastic explanation is that when fractures are newly opened, the internal pressure in the rock is lower than the fracture opening pressure, and the fracture is held open by the fracture water pressure. As time progresses the pressure diffuses into the rock, and the rock relaxes towards its initial geometry, closing the fracture. The reverse occurs upon depressurizing the fracture. Biological and chemical explanations have also been offered. This effect might be expected at FORGE and in EGS systems.

\subsubsection{Thermoelasticity}

Thermoelastic effects have been observed in two significant areas on this project. First, the mine drift was cooled over decades of ventilation. Most (but not all) fracture growth from stimulations proceeded towards the cooler drift as predicted by early models, providing an element of validation of the thermoelastic effect. Second, the injection of cool water into the warm fractured rock initially resulted in an increase in permeability, and the opposite effect was observed when the temperature of the injected water increased, prior to the observation of the poroelastic effect reducing fracture permeability. This effect should be expected at FORGE and in EGS systems where cooler water will be introduced into hot rock.

\subsubsection{Local Geology}

A number of local geology effects have been observed to affect stimulation and flow behavior. kISMET drilling from meters away showed few fractures, however EGS Collab drilling identified many fractures, particularly in the upper regions of the test bed. ERT data concurred with the core data that the geology was more complicated than originally assumed based on earlier observations [20]. Analysis of tomography/full-waveform inversion of campaign seismic data revealed that the host rock can be represented by a horizontal transverse isotropic (HTI) medium [37].

Stress measurements from the vertical borehole on the 4100 level highlight effects of local geology. The unexpected rhyolite body on the 4100 level has a lower minimum principal stress separating the higher minimum principal stress amphibolite beneath the rhyolite from a medium value minimum principal stress amphibolite above the rhyolite.

The role of natural fractures can be estimated a-priori if enough information including stress, fracture orientations, and interconnectedness can be determined by characterization. Discrete fracture network models graphically summarize this information, making interpretation of stimulation behavior more tractable.

\section{Addressing EGS Challenges}

EGS technological challenges are being addressed in the EGS Collab project, FORGE, and other field projects. The issues are complex, however, and additional investigations will be needed. Research needs include better understanding and continued improvements to rock stimulation methods to allow better subsurface heat exchanger creation, and better geophysical imaging and monitoring of the resulting permeability enhancement that occurs. Like in an industrial heat exchanger, uniformly distributed flow and knowing how the fluids move through the heat exchanger are key to optimizing operation.

In addition to stimulating rock and creating flow paths, controlling flow paths will be critical. This will require development of zonal isolation techniques and perhaps the use of diverters (e.g. silica gels that set in fast flow paths). Thus, proper stimulation, combined with yet-tobe-engineered, well-based zonal isolation tools will be needed. Zonal isolation tools combined with fast path control techniques will allow optimal distribution of flow.

During reservoir operation, chemical disequilibrium between the injected water and the rock will cause dissolution and precipitation reactions that may affect reservoir sustainability and production. Additional understanding of these complex processes and engineering techniques to control reservoir sustainability will be needed. Although many techniques useful in shallow applications cannot be directly implemented at depth either due to drilling costs or high temperature/ 
pressure conditions, new tools and creative applications of current tools are needed.

The challenges to implement EGS are significant but the rewards will be great. Efforts such as FORGE, EGS Collab, and other projects around the world are appropriate and necessary steps towards minimizing these challenges. Multi-disciplinary approaches are needed to bring the optimal thermal, mechanical, chemical, hydrological, geophysical, engineering and other expertise together to address these challenges.

\section{Acknowledgements}

This material was based upon work supported by the U.S. Department of Energy, Office of Energy Efficiency and Renewable Energy (EERE), Office of Technology Development, Geothermal Technologies Office, under Award Number DE-AC02-05CH11231 with LBNL and other awards to other national laboratories. The United States Government retains, and the publisher, by accepting the article for publication, acknowledges that the United States Government retains a non-exclusive, paid-up, irrevocable, world-wide license to publish or reproduce the published form of this manuscript, or allow others to do so, for United States Government purposes. The research supporting this work took place in whole or in part at the Sanford Underground Research Facility in Lead, South Dakota. The assistance of the Sanford Underground Research Facility and its personnel in providing physical access and general logistical and technical support is gratefully acknowledged. We thank the drillers of Agapito Associates, Inc., for their skill and dedicated efforts to create our test bed boreholes. The earth model output for this paper was generated using Leapfrog Software. Copyright (C) Seequent Limited. Leapfrog and all other Seequent Limited product or service names are registered trademarks or trademarks of Seequent Limited.

\section{References}

1. C.F. Williams, M.J. Reed, R.H. Mariner, J. DeAngelo and S.P. Galanis, Jr., Assessment of moderate- and high-temperature geothermal resources of the United States, U.S.G. Survey, Editor. 2008. p. 4.

2. C. Augustine, Update to Enhanced Geothermal System Resource Potential Estimate. GRC Transactions, 2016. 40: p. 6.

3. T.J. Kneafsey, D. P.F., J.B. Ajo-Franklin, Y. Guglielmi, C.A. Valladao, D.A. Blankenship, P.C. Schwering, H.A. Knox, M.D. White, T.C. Johnson, C.E. Strickland, V.R. Vermuel, J.P. Morris, P. Fu, E. Mattson, G.H. Neupane, R.K. Podgorney, T.W. Doe, L. Huang, L.P. Frash, A. Ghassemi, W. Roggenthen and the EGS Collab Team, EGS Collab Project: Status, Tests, and Data, in 53rd US Rock Mechanics/Geomechanics Symposium. 2019: New York, NY, USA. p. 19.

4. J.W. Tester, B.J. Anderson, D.D. Blackwell, R. DiPippo, E. M. Drake, J. Garnish, B. Livesay, M.C. Moore, K. Nichols, S. Petty, M.N. Toksoz and J. R.
W. Veatch, The Future of Geothermal Energy, Impact of Enhanced Geothermal Systems (EGS) on the United States in the 21st Century. 2006, INEL/EXT-0611746, MIT/DOE (2006). p. 372.

5. J. Moore, J. McLennan, R. Allis, K. Pankow, S. Simmons, R. Podgorney, P. Wannamaker, J. Bartley, C. Jones and W. Rickard, The Utah Frontier Observatory for Research in Geothermal Energy (FORGE): An International Laboratory for Enhanced Geothermal System Technology Development, in 44th Workshop on Geothermal Reservoir Engineering. 2019: Stanford University, Stanford, California.

6. H. Knox, P. Fu, J. Morris, Y. Guglielmi, V. Vermeul, J. Ajo-Franklin, C. Strickland, T. Johnson, P. Cook, C. Herrick, M. Lee and the EGS Collab Team, Fracture and Flow Designs for the Collab/Sigma-V Project in GRC Transactions, Vol. 41, 20172017.

7. J.P. Morris, P. Fu, P. Dobson, J. Ajo-Franklin, T.J. Kneafsey, H. Knox, D. Blankenship, M.D. White, J. Burghardt, T.W. Doe and the EGS Collab Team, Experimental Design for Hydrofracturing and Fluid Flow at the DOE EGS Collab Testbed, in 52nd U.S. Rock Mechanics/Geomechanics Symposium. 2018, American Rock Mechanics Association: Seattle, Washington. p. 11.

8. J.P. Morris, P. Fu, P. Dobson, J. Ajo-Franklin, T.J. Kneafsey, H. Knox, D. Blankenship, M.D. White, J. Burghardt, T.W. Doe and Egs Collab Team, Experimental Design for Hydrofracturing and Fluid Flow at the DOE EGS Collab Testbed, in 52nd U.S. Rock Mechanics/Geomechanics Symposium. 2018, American Rock Mechanics Association: Seattle, Washington. p. 11.

9. C.M. Oldenburg, P.F. Dobson, Y. Wu, P.J. Cook, T.J. Kneafsey, S. Nakagawa, C. Ulrich, D.L. Siler, Y. Guglielmi, J. Ajo-Franklin, J. Rutqvist, T.M. Daley, J.T. Birkholzer, H.F. Wang, N.E. Lord, B.C. Haimson, H. Sone, P. Vigilante, W.M. Roggenthen, T.W. Doe, M.Y. Lee, M. Ingraham, H. Huang, E.D. Mattson, J. Zhou, T.J. Johnson, M.D. Zoback, J.P. Morris, J.A. White, P.A. Johnson, D.D. Coblentz and J. Heise, Hydraulic fracturing experiments at $1500 \mathrm{~m}$ depth in a deep mine: Highlights from the KISMET project, in 42nd Workshop on Geothermal Reservoir Engineering. 2017: Stanford University. p. 9.

10. Q. Zhou, C.M. Oldenburg, T.J. Kneafsey and the EGS Collab Team, Modeling Transport of Multiple Tracers in Hydraulic Fractures at the EGS Collab Test Site, in PROCEEDINGS, 43rd Workshop on Geothermal Reservoir Engineering. 2018: Stanford University, Stanford, California.

11. T.W. Doe, R. McLaren and W. Dershowitz, Discrete Fracture Network Simulations of Enhanced Geothermal Systems, in 39th Workshop on Geothermal Reservoir Engineering. 2014: Stanford University. p. 11.

12. P. Fu, M. Schoenball, J. Morris, J. Ajo-Franklin, H. Knox, T. Kneafsey, J. Burghardt, M. White and the EGS Collab Team, Microseismic Signatures of Hydraulic Fracturing: A Preliminary Interpretation of Intermediate-Scale Data from the EGS Collab Experiment, in 44th Workshop on Geothermal 
Reservoir Engineering. 2019: Stanford University, Stanford, California.

13. M. White, T. Johnson, T. Kneafsey, D. Blankenship, P. Fu, H. Wu, A. Ghassemi, J. Lu, H. Huang, G. Neupane, C. Oldenburg, C. Doughty, B. Johnston, P. Winterfeld, R. Pollyea, R. Jayne, A. Hawkins, Y. Zhang and the EGS Collab Team, The Necessity for Iteration in the Application of Numerical Simulation to EGS: Examples from the EGS Collab Test Bed 1, in 44th Workshop on Geothermal Reservoir Engineering. 2019: Stanford University, Stanford, California.

14. P. Winterfeld, B. Johnston, K. Beckers, Y.-S. Wu and the EGS Collab Team, Code Modifications for Modeling Chemical Tracers and Embedded Natural Fractures at EGS Collab, in 44th Workshop on Geothermal Reservoir Engineering. 2019: Stanford University, Stanford, California.

15. H. Wu, P. Fu, J.P. Morris, E.D. Mattson, A.J. Hawkins, Y. Zhang, R.R. Settgast, F.J. Ryerson and the EGS Collab Team, Characterizing Fracture Flow in EGS Collab Experiment Based on Stochastic Modeling of Tracer Recovery, in 44th Workshop on Geothermal Reservoir Engineering. 2019: Stanford University, Stanford, California.

16. H. Wu, P. Fu, J.P. Morris, R.R. Settgast, F.J. Ryerson and the EGS Collab Team, A Numerical Scheme to Reduce Numerical Diffusion for Advection-Dispersion Modeling: Validation and Application, in 44th Workshop on Geothermal Reservoir Engineering. 2019: Stanford University, Stanford, California.

17. Y. Chen, L. Huang, M. Schoenball, J. Ajo-Franklin, T. Kneafsey and the EGS Collab Team, Real-Time Microearthquake Event Detection and Location in Anisotropic Media Using a Multiscale Scanning Approach for EGS Collab Experiments in 44th Workshop on Geothermal Reservoir Engineering. 2019: Stanford University, Stanford, California.

18. L.P. Frash, J.W. Carey, N.J. Welch and the EGS Collab Team, EGS Collab Experiment 1: Geomechanical and Hydrological Properties by Triaxial Direct Shear, in 44th Workshop on Geothermal Reservoir Engineering. 2019: Stanford University, Stanford, California.

19. H. Huang, G.H. Neupane, R. Podgorney, E. Mattson and the EGS Collab Team, Mechanistically Modeling of Hydraulic Fracture Propagation and Interaction with Natural Fractures at EGS-Collab Site in 44th Workshop on Geothermal Reservoir Engineering. 2019: Stanford University, Stanford, California.

20. T. Johnson, C. Strickland, H. Knox, J. Thomle, V. Vermuel, C. Ulrich, T. Kneafsey, D. Blankenship and the EGS Collab Team, EGS Collab Project Electrical Resistivity Tomography Characterization and Monitoring Status, in 44th Workshop on Geothermal Reservoir Engineering. 2019: Stanford University, Stanford, California.

21. J. Lu and A. Ghassemi, Coupled THMS Modeling of Fractured Reservoir Stimulation with Application to EGS Collab, in 44rd Workshop on Geothermal Reservoir Engineering. 2019: Stanford University, Stanford, California.
22. E. Mattson, Y. Zhang, A. Hawkins, T. Johnson, J. AjoFranklin, G. Neupane and the EGS Collab Team, Preliminary Collab Fracture Characterization Results from Flow and Tracer Testing Efforts in 44th Workshop on Geothermal Reservoir Engineering. 2019: Stanford University, Stanford, California.

23. W. Pan, L. Huang, K. Gao, J. Ajo-Franklin, T.J. Kneafsey and the EGS Collab Team, Anisotropic Full-Waveform Inversion and Least-Squares ReverseTime Migration of CASSM Data for Experiment I of the EGS Collab Project in 44th Workshop on Geothermal Reservoir Engineering. 2019: Stanford University, Stanford, California.

24. M. Schoenball, J. Ajo-Franklin, D. Blankenship, P. Cook, P. Dobson, Y. Guglielmi, P. Fu, T. Kneafsey, H. Knox, P. Petrov, M. Robertson, P. Schwering, D. Templeton, C. Ulrich, T. Wood and the EGS Collab Team, Microseismic monitoring of mesoscale stimulations for the DOE EGS Collab project at the Sanford Underground Research Facility, in 44th Workshop on Geothermal Reservoir Engineering. 2019: Stanford University, Stanford, California.

25. D. Templeton, J. Morris, M. Schoenball, T. Wood, M. Robertson, P. Cook, P. Dobson, C. Ulrich, J. AjoFranklin, T. Kneafsey, P. Schwering, D. Blankenship, H. Knox and EGS Collab Team, Microseismic Correlation and Cluster Analysis of DOE EGS Collab Data, in 44th Workshop on Geothermal Reservoir Engineering. 2019: Stanford University, Stanford, California.

26. J. Weers and J. Huggins, Getting Data Out of the Ground: Modern Challenges Facing EGS Collab, the DOE Geothermal Data Repository, and the Geothermal Industry, in 44th Workshop on Geothermal Reservoir Engineering. 2019: Stanford University, Stanford, CA.

27. Z. Ye, A. Vachaparampil, X. Zhou, A. Ghassemi and T. Kneafsey, Failure Behavior of the Poorman Schist and Its Fractures from EGS Collab Stimulation Site, in 44th Workshop on Geothermal Reservoir Engineering. 2019: Stanford University, Stanford, California.

28. M. White, P. Fu, H. Huang, A. Ghassemi and the EGS Collab Team, The Role of Numerical Simulation in the Design of Stimulation and Circulation Experiments for the EGS Collab Project in GRC Transactions, Vol. 41, 20172017.

29. Y. Guglielmi, F. Cappa, H. Lançon, J.B. Janowczyk, J. Rutqvist, C.F. Tsang and J.S.Y. Wang, ISRM Suggested Method for Step-Rate Injection Method for Fracture In-Situ Properties (SIMFIP): Using a 3Components Borehole Deformation Sensor, in The ISRM Suggested Methods for Rock Characterization, Testing and Monitoring: 2007-2014, R. Ulusay, Editor. 2013, Springer-Verlag: Wein.

30. Y. Guglielmi, F. Cappa, J.-P. Avouac, P. Henry and D. Elsworth, Seismicity triggered by fluid injectioninduced aseismic slip. Science, 2015. 348(6240): p. 1224.

31. E. Mattson, G. Neupane, A. Hawkins, J. Burghardt, M. Ingraham, M. Plummer and the EGS Collab Team, Fracture Tracer Injection Response to Pressure 
Perturbations at an Injection Well. GRC Transactions, 2019. 43: p. 9.

32. M.D. White, P. Fu, A. Ghassemi, H. Huang, J. Rutqvist, B. Johnston and the EGS Collab Team, Numerical Simulation Applications in the Design of EGS Collab Experiment 1, in PROCEEDINGS, 43rd Workshop on Geothermal Reservoir Engineering. 2018: Stanford University, Stanford, California.

33. P. Fu, M. White, J. Morris, T. Kneafsey and E.C. Team, Predicting Hydraulic Fracture Trajectory Under the Influence of a Mine Drift in EGS Collab Experiment I, in PROCEEDINGS, 43rd Workshop on Geothermal Reservoir Engineering. 2018: Stanford University, Stanford, California.

34. J.B. Ajo-Franklin, M. Schoenball, T. Wood, M. Robertson, P. Petrov, L. Huang, T.J. Kneafsey, P. Schwering, D. Blankenship, H. Knox and E.C. Team, Imaging Hydraulic Fracture Propagation Using Semi-Permanent Continuous Active Seismic Source Monitoring: Results from the DOE EGS Collab Experiment, in American Geophysical Union Fall Meeting 2018. 2018, American Geophysical Union: Washington DC.

35. B. Chi, L. Huang, K. Gao, J. Ajo-Franklin, T.J. Kneafsey and the EGS Collab Team, Anisotropic Imaging of Created Fractures in EGS Collab Experiments Using CASSM Data, in 45th Workshop on Geothermal Reservoir Engineering. 2020: Stanford University, Stanford, California. p. 6.

36. Y. Zhang, C. Doughty, L. Pan, T. Kneafsey and Egs Collab Team, What Could We See at the Production Well Before the Thermal Breakthrough?, in PROCEEDINGS, 43rd Workshop on Geothermal Reservoir Engineering. 2018: Stanford University, Stanford, California.

37. K. Gao, L. Huang, H.A. Knox, P.C. Schwering, C.R. Hoots, J. Ajo-Franklin, T. Kneafsey and the EGS Collab Team, Anisotropic Elastic Properties of the First EGS Collab Testbed Revealed from the Campaign Cross-Borehole Seismic Data, in 45th Workshop on Geothermal Reservoir Engineering. 2020: Stanford University, Stanford, California. p. 11. 